\title{
The Phenomenon of Learning in a Museum in a Modern Educational Space: Opportunities of Using Smart Technologies
}

Oleksiy Karamanov / e -mail: oleksiy.karamanov@1nu.edu.ua Ivan Franko National University of Lviv, Ukraine

Olha Bilyakovska / e -mail: olha.bilyakovska@1nu.edu.ua Ivan Franko National University of Lviv, Ukraine

Karamanov, O - Bilyakovska, O. (2020). The Phenomenon of Learning in a Museum in a Modern Educational Space: Opportunities of Using Smart Technologies. Czech-Polish Historical and Pedagogical Journal, 12/2, 146 - 152.

https://doi.org/10.5817/cphpj-2020-028

The article analyzes the peculiarities of organizing learning in a museum in the system of smart education with modern smart technologies aimed at the process of gaining skills and competencies for flexible and adapted interaction with social, economic and technological environment. Smart technologies are emphasized to not only allow creating the effect of presence but also to advance the content sharing, change its quality, and ensure the possibility of communication between all the participants of the educational process. The phenomenon of learning in a museum is viewed in the context of gamification, edutainment, the storytelling technique and the project method. The opportunities of using smart technologies in museums as centres of communication, studying and leisure in the context of a modern knowledge society are defined.

Key words: learning in a museum; smart technologies; smart education; museum pedagogy; an educational space; a museum space

Modern educational technologies provide the creation and the analysis of most diverse contexts of learning, which allows using them for current didactic purposes. Regarding this, the idea of interdisciplinary is more and more often mentioned in modern concepts of effective learning, which, for example, enables the combination of efforts of didactics (theory and methodology of learning), cultural studies (as a constituent of any course) and effective information technologies.

In particular, the subject mentioned is in a way closer to humanitarian disciplines that require more problematization, generalization and visualization of learning material.

The effects of such a combination give an opportunity to realize bold ideas that allow to capture a necessary image, an approach, a sentence not only in theory but 
in its practical application, particularly via cultural artifacts created by humans and also elements of both material and non-material heritage.

Apparently, the issue is about museums with their terrific cultural potential and educational functions which are also very important. Developing and setting the ideas of qualitative learning in their space, museums have become an inseparable part of the process of academic and informal education in many countries over the last 20 years.

In this context, smart museums using a unified system of communication for both museums and visitors hold a special place. First of all, one should mention mobile applications which give every visitor with a mobile phone (smartphone) a possibility to receive necessary audio, video, photo and text information about all the museum exhibits and let a visitor manage the process of following the exhibition independently. In addition, the location of exhibits in the museum is also important for the possibility of their effective usage in the process of learning new material and in organizing the learning process. Another necessary element involves building a virtual museum on the basis of a real exposition.

The article aims at analyzing the possibilities of using smart education and smart technologies in museums as centres of communication, studying and leisure in the context of a modern knowledge society.

The issues of applying smart education in a museum space have been a subject of research papers by various scholars who study the peculiarities of designing a smart museum (A Chianese, ${ }^{1}$ D. Sacher ${ }^{2}$ ) and building effective digital culture (T. Giannini, J. P. Bowen ${ }^{3}$ ), review various aspects of its creation (B. Dawson, D. Edmundson, ${ }^{4}$ S. Marchenkov ${ }^{5}$ ), analyze the conceptual framework of learning

${ }^{1}$ Chianese, A. - Piccialli F. (2014). Designing a smart museum: When cultural heritage joins iot. In $8^{\text {th }}$ International conference on next generation mobile applications, services and technologies. NGMAST, Institute of Electrical and Electronics Engineers Inc., pp. 300 - 306.

2 Sacher, D. - Weyers, B. - Biella, D. - Luther W. (2014). Smart Museums - Exploiting Generative Virtual Museums. In Hervás R., Lee S., Nugent C., Bravo J. (eds) Ubiquitous Computing and Ambient Intelligence. Personalisation and User Adapted Services. UCAmI, Lecture Notes in Computer Science, Springer, Cham, vol 8867.

3 Museums and digital culture: new perspectives and research (2019). T. Giannini - J. P. Bowen (eds), Cham, Springer, 590 pp.

${ }^{4}$ Dawson, B. - Edmundson, D. (2018). Building a smart museum: Tackling in-gallery challenges with digital experience at scale, MW 2018. Published March 16, 2018. https://mw18.mwconf.org/paper/building-a-smart-museum-tackling-in-gallery-challengeswith-digital-experience-at-scale/

5 Marchenkov, S. - Vdovenko, A. - Petrina, O. - Korzun, D. (2017). Smart museum of everyday life history. In Software design and implementation of the semantic layer. 21st Conf. Open Innovations Association FRUCT, Nov 2017, pp. 224 - 230. 
in a smart museum (T. Collins, ${ }^{6}$ I. Kang ${ }^{7}$ ); yet, this subject is not well studied and requires additional research.

SMART is known to be an acronym that stands for:

- $\mathrm{S}=$ Specific

- $\mathrm{M}=$ Measurable

- $\mathrm{A}=$ Achievable

- $\mathrm{R}=$ Relevant/Realistic/Results Focused

- $\mathrm{T}=$ Timely/Trackable

In scholars view, smart education reflects such an educational paradigm that lies in the basis of a new type of the system of education. The realization of the smart education paradigm is directed into the process of gaining skills and competencies for flexible and adapted interaction with social, economic and technological environment. Smart education must create opportunities for using the advantages of a global information society that concern ensuring educational needs and interests.

Main principles of smart education are:

- using relevant information of a educational programme for solving learning tasks;

- arranging pupils and students independent, cognitive, research and project activity;

- realization of a learning process in a distributed (distinguished) education environment;

- students interaction with a professional community;

- flexible educational trajectories, individualization of a learning process;

- versatility of educational activity.

While modelling peculiarities of applying these principles to a museum space, it is worth considering a type of an exhibition and comments to exhibits that should reflect modern approaches to actualization of cultural heritage, on the one hand, and real-time information referring solving practical learning tasks, on the other.

For this reason and for better estimation and promotion of cultural heritage, it is preferable to introduce cultural objects with a possibility of their interaction

${ }^{6}$ Collins, T. D. - Mulholland, P. - Zdrahal Z. (2009). Using mobile phones to map online community resources to a physical museum space. International Journal of Web Based Communities, 5, pp. 18 - 32.

7 Kang, I. A. - Lee S. H. (2014). A Conceptual Framework for Smart Museum Education. In Museums and the Web Asia, N. Proctor \& R. Cherry (eds). Silver Spring, MD: Museums and the Web. Published October 2, 2014.

8 Hurevych, R. (2016). Smart-osvita - nova paradyhma suchasnoi systemy osvity. Teoriia i praktyka upravlinnia sotsialnymy systemamy, No. 4, 71 - 78, http://nbuv.gov.ua/UJRN/Tipuss _2016_4_9

9 Ibid., p. 76. 
with people, environments, and other objects as well as a possibility of transferring relevant knowledge to users via multimedia. ${ }^{10}$

Increase of the effectiveness of museum communication for the realization of learning tasks ensures the use of gamification and edutainment, which means unifying goals of both a game and learning when a game is used as a teaching tool. A storytelling technique deserves a special place since it makes possible to animate the communication process by listeners active involvement into the process of creating and telling stories.

Use of the project method (the case method) is also an important point while teaching in a museum space that lets the students independently choose, research, draw analogies and parallels, classify and use necessary information with the aim of its further representation in the form of ready-made projects, qualitative tasks and performances, etc.

In addition, it is necessary to view a museum space as an important element of a widely interpreted around-museum space that involves the realization of elements of distance learning and the creation of a parallel virtual museum exhibition. Such an exhibition provides best possible opportunities for working in a relevant virtual environment considering pupils and students needs and possibilities; it also promotes configuration changes of a learning space.

It acquires special relevance in terms of:

- a choice of various teaching tools that help to gain necessary information effectively;

- using flexible educational trajectories in the context of personalization, versatility and openness of professional learning environment;

- making new cultural creative products based on wide interpretation of museum exhibits;

- applying ideas of world science in the process of developing cognitive interest and motivation to studying in a museum;

- providing equal and free access to knowledge in a museum (= museum knowledge') as the living embodiment of the concept of openness in education.

Smart technologies allow not only creating the effect of presence but also advancing the content sharing, changing its quality, and ensuring the possibility of communication between all the participants of the educational process. A special emphasis is made on the content and resources of learning. In this context, it is important to constantly adjust educational resources, supplement information, and ensure flexibility in development and use of necessary content.

10 Chianese, A. - Piccialli, F., Op. cit. 
According to the researches, ${ }^{11}$ a modern museum space contains enough specialized museums representing most fields of human activity, which creates necessary conditions for using them during the learning process.

For instance, human need for transferring and transporting of goods and people is shown on exhibitions at the museums of cars, public transport, subway, aviation and post. The need for food involves learning and researching the evolution of human interaction with water, minerals, plants, animals and insects. This can be found due to the exhibitions of water, salt, bread, beekeeping, zoology, natural sciences, history of veterinary and local history museums.

The need for clothes is also important for human society. For example, the process of making and keeping clothes of a good quality is reflected in the exhibitions in the museums of embroidery, fashion history, costume and style history. Meeting human needs and supporting life is also connected with medicine and social hygiene, which is seen on the exhibitions of medicine museums and pharmacy museums.

Various significant needs for social and self-realization of a person in a family, a community, a state are displayed on the exhibitions of the museums of toys, books, circus art, art and fine arts. ${ }^{12}$

Nowadays, smart education may be definitely called a main feature of the future of education with the extension of time, space, teaching materials and methods that overcomes limited possibilities of traditional training courses.

A museum space implements such smart learning since it involves flexible learning in an interactive environment (a primary element of success of any class in a museum is flexibility at the stages of its planning and realization), fast visitor's adaptation to a changing environment (the use of the elements of virtual reality (VR) and augmented reality (AR) creates necessary conditions for it), free access to various information content (a museum builds creative thinking skills when the visitors evaluate historical, social, political and other contexts of knowledge in a different way in the process of communication).

Based on this, museums must provide interactive communication between students, experts and museums without any limits of time and space with the museum devices, on the website and/or other devices. Students participation and interaction should also be simplified. The best direction of intellectual learning in a museum is the creation of such a system that reflects the principles of independent, constant, project and mutual learning with the use of intellectual technologies and effective pedagogical interaction.

11 Hubytskyi, R. - Melnyk, H. (2018). Virtualnyi muzei torhivli, Smart-osvita: resursy ta perspektyvy: materialy III Mizhnar. nauk.-metod. konf. (Kyiv, 7 hrudnia 2018 r.): tezy dopovidei, Kyiv: Kyiv. nats. torh.-ekon. un-t, pp. 198 - 200.

12 Hubytskyi, R. - Melnyk, H., Op. cit, pp. $199-200$.

13 Kang, I. A. - Lee, S. H., Op. cit. 
The spread of smart technologies in a museum provides opportunities for managing and personalizing the experience. However, planning is necessary for using these opportunities, particularly for building necessary architecture of management and standards that have sense for a particular museum. ${ }^{14}$

Due to this, users of museum smart services - both museum visitors and personnel - are supported by such effective and efficient means as mobility of museum users, service personalization and opportunities of common work. ${ }^{15}$

The idea of smart education in a museum space is implemented in many countries of Western and Eastern Europe as well as in Asia and the USA. The best practices of such implementation include Smart Museum of Art in Chicago (the USA), SMART Museum Château Musée de Dieppe (France), Smart Museum projects C-Park (Italy), The Hubei Provincial Museum (China), Smart Museum of Everyday Life History in Petrozavodsk (Russia), Smart Museum in the Knight Hall of the Palanok Castle in Mukachevo (Ukraine) and others.

In the context of our research, special attention should be paid to virtual museums which are created by combining large-scale collections between museums and exhibitions galleries, and include digital images of monuments that are preserved and exhibited in hundreds of museums all over the world.

Adaptive peculiarities of a virtual 3D museum include architectural design, location of the exhibits, supplementing relevant studying materials (sometimes multilingual), navigation tools or modes of users interaction with the objects of different levels of complexity. In some cases, the exhibition environment is built dynamically so that software controls visitors behaviour for developing adaptive tours that determine their preferences during a visit. ${ }^{16}$

Both resources of fixed servers and possibilities of cloud technologies may serve as means of accumulating necessary information in such museums. Personal computers in computer classrooms, 3D projectors, LightPro projectors, and opportunities of distance learning can be used for exhibiting necessary information. Information of the exhibits can be used for role and business games, creation of business projects, portfolios, advertisement, educational films, and support of training simulations on the examples of various interpersonal relations in the societies of all the epochs ${ }^{17}$.

While determining the conditions of using smart technologies, it is necessary to pay attention to potential risks of their use. In particular, it is about:

- young users being sure to always find answers to all the questions on their smartphone or gadget;

- decrease of the level of interest in reading and disability to develop one's thought or problem and ways of solving it clearly;

\footnotetext{
14 Dawson, B. - Edmundson, D., Op.cit.

15 Marchenkov, S. - Vdovenko, A. - Petrina, O. - Korzun, D., Op.cit., p. 229.

16 Sacher, D. - Weyers, B. - Biella, D. - Luther, W., Op.cit.

17 Hubytskyi, R. - Melnyk, H., Op. cit, p. 199.
} 
- the lack of skills for working with large portions of a text as well as for its analysis;

- low level of creative thinking and creativity;

- development of non-creative thinking with film, virtualized consciousness.

Considering mentioned above, a few basic ideas may be outlined that help to understand the role of museum teaching in the context of using smart technologies:

- broad visualization of a variety of learning contexts, which creates opportunities for qualitative learning;

- individualization and personalization of the educational process that allows taking into consideration the individuality of each person to its fullest;

- opportunities for pupils and students to build their own knowledge constructions (content of knowledge) on the grounds of the ideas of connectivism as a new philosophy of the $21^{\text {st }}$ century.

Thus, applying smart education and smart technologies in museums in the context of a modern knowledge society involves:

- maximal visualization of information by using technologies of virtual reality (VR) and augmented reality (AR) that allow moving in time and space;

- computerization of classrooms and a museum space by spreading the practice of using iPads an laptops in the educational process;

- the change of configuration of an educational space in a museum and classrooms via integrated technologies that enable the effective organization of teamwork;

- the organization of a personal learning environment and adaptive learning in a museum space when education acquires individual value for each student and allows them to make some adjustments;

- the use of the project method (the case method) with elements of gamification, edutainment and storytelling in order to fully exploit the learning potential of a museum space.

We see the perspectives of further research in this direction in studying the opportunities for the development of integrated smart programmes for diversification of learning content of a museum in the process of communication with various target groups of visitors. 